\title{
Competência: distintas abordagens e implicações na formação de profissionais de saúde
}
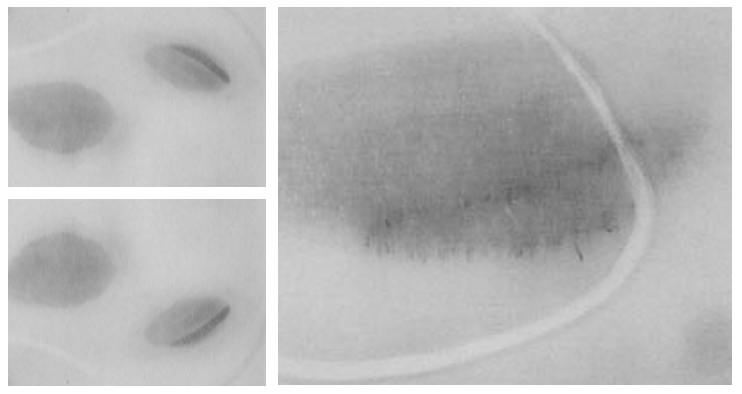

Valéria Vernaschi Lima ${ }^{1}$

LIMA, V. V. Competence: different approaches and implications in the training of healthcare professionals. Interface - Comunic., Saúde, Educ., v.9, n.17, p.369-79, mar/ago 2005.

This article presents some of the main conceptions of competence in the educational field, analyzing these distinctive approaches according to the theoretical reference that is their base, their component dimensions and consequent implications for curriculum organization. In line with the new meaning provided by the dialogical approach to competence, this article points to an integration of theory and practice in the education of healthcare professionals.

KEY WORDS: Education; health; curriculum; competence; professional practice.

Este texto apresenta algumas das principais concepções sobre currículos orientados por competência, analisando essas distintas abordagens em função do referencial teórico que as fundamenta, de suas dimensões constituintes e das conseqüentes implicações na organização curricular. Aponta, no novo significado trazido pela abordagem dialógica de competência, um caminho para a integração da teoria e da prática na formação de profissionais de saúde.

PALAVRAS-CHAVE: Educação; saúde; currículo; competência; prática profissional.

\footnotetext{
${ }^{1}$ Professora, Faculdade de Medicina de Marília, Marília, SP. <valeriavl@uol.com.br>
} 
No senso comum, encontram-se dois enfoques semânticos para o termo competência: um relacionado à legitimidade atribuída por lei ou por reconhecimento a uma pessoa ou organização para apreciar ou julgar determinada questão ou pleito; e outro relacionado ao reconhecimento de características pessoais (qualidades) vinculadas à capacidade e idoneidade para resolver certos assuntos, inclusive os de natureza profissional (Hillau, 1994).

No mundo do trabalho, pode-se observar a transição do conceito clássico de qualificação profissional para uma concepção de competência, em função das novas demandas do setor produtivo e da falência dos métodos destinados a adaptar as pessoas ao mercado e aos postos de trabalho. A crise na qualificação decorre da inserção das economias em mercados globalizados, da crescente exigência de produtividade e competitividade e da vertiginosa incorporação de novas tecnologias que requerem flexibilidade $e$ polivalência dos trabalhadores (Valle, 2003).

Há, neste campo, uma polarização acerca da natureza desse deslocamento conceitual (Ramos, 2001). Alguns sociólogos interpretam que as mudanças nas funções dos trabalhadores com a incorporação de atividades mais intelectuais, subjetivas e reflexivas servem aos interesses do capital e que, por isso, representam uma renovação do capitalismo em função de suas novas necessidades (Boltansky \& Chiapello, 2001). Por outro lado, Burawoy (1979) aponta que o local e as relações de trabalho produzem, de modo dialético, não só conflitos, mas também consensos; não só reprodução, mas também transformação. Ressalta que os novos conceitos de produção são resultantes de construções histórico-político-econômicas que requerem novas relações sociais, uma vez que o próprio processo de trabalho se transforma em objeto de luta e o controle sobre ele deixa de ser exclusivo de um dos lados. Nesse sentido, a gestão do trabalho foi ampliada para além do produto e precisou incorporar as inter-relações entre as pessoas, ganhando uma abordagem intersubjetiva e distinta daquela estritamente objetivista, característica da qualificação nos modelos taylorista-fordista (Valle, 2003).

Embora haja o reconhecimento de que a ampliação de autonomia $e$ integração dos trabalhadores no processo de trabalho tenha um recorte determinado pelo interesse e visão da direção das organizações, a gestão matricial, a horizontalização dos organogramas, a desconcentração do poder de planejar e de decidir e a construção de espaços coletivos com capacidade de análise e reflexão possibilitam a constituição e o fortalecimento de sujeitos e da democracia, no sentido da alteração dos esquemas de dominação (Campos, 2000). Para Merleau-Ponty (1980, p.275), “a regulação que circunscreve o indivíduo não o suprime (....), sendo que o maior interesse dessa nova investigação consiste em substituir as antinomias por relações de complementariedade".

Essa polarização de interpretações, também reproduzida nos campos da administração e da educação, vem sendo traduzida nas múltiplas definições de competência que, apesar de ser um tema bastante debatido nas últimas três décadas, mantém-se polissêmico, variando seu significado segundo autor, setor e país.

$\mathrm{Na}$ literatura educacional, pode-se verificar três relevantes abordagens 
conceituais sobre competência: uma considera competência como sendo uma coleção de atributos pessoais; outra vincula o conceito aos resultados observados/obtidos (tarefas realizadas) e uma terceira propõe a noção de competência dialógica, originada na combinação de atributos pessoais para a realização de ações, em contextos específicos, visando atingir determinados resultados.

$\mathrm{Na}$ abordagem dialógica, há um resgate integrador dos dois enfoques semânticos do termo competência, uma vez que coloca os atributos pessoais em relação com distintas construções sociais que legitimam esses atributos de acordo com a história das sociedades em diferentes épocas.

A definição do que uma determinada sociedade considera como sendo legítimo e/ou legal é uma construção determinada pela história, pela cultura e pelo desenvolvimento técnico-científico e ético-cultural dessa sociedade. Nesse sentido, tanto os processos de formação como os de certificação profissional e de acreditação institucional, também colocam a questão da competência no campo dos conflitos de interesse, das relações sócio-econômicas, das disputas ideológicas e de poder nas sociedades (Ribeiro, 2003; Hernández, 2002).

A abordagem dialógica de competência reconhece e considera a história das pessoas e das sociedades nos seus processos de reprodução ou de transformação dos saberes e valores que legitimam os atributos e os resultados esperados numa determinada área profissional. Esta explicitação permite um processo mais aberto de exploração das distintas concepções, interesses, valores e ideologias, que invariavelmente governam $e$ determinam a intencionalidade dos processos educativos, porém nem sempre são discutidos de um modo mais participativo e democrático pela sociedade. Nesse sentido, a abordagem guarda relação com a compreensão interacionista da relação escola-sociedade na qual a escola é potencialmente capaz de influenciar a sociedade, sendo por ela constituída (Moglika, 2003).

Programas educacionais orientados por competência A definição de currículos orientados por competência requer uma opção conceitual em relação ao que se define como competência. As matrizes referenciais para as diferentes escolhas têm raízes histórico-sociais nos países nos quais foram desenvolvidas e representam disputas ideológicas nos campos da educação e do trabalho.

As tendências hegemônicas (condutivisvo e funcionalismo) são predominantes nos Estados Unidos e na Inglaterra. A abordagem condutivista advém do comportamentalismo da pedagogia e psicologia. Estruturada e defendida por educadores e psicólogos dos Estados Unidos, guarda relação com a eficiência e adaptação para o mercado de trabalho. $\mathrm{O}$ desempenho efetivo é o elemento central nessa abordagem, voltada à qualificação para o emprego (Valle, 2003).

O funcionalismo, vinculado ao pensamento funcionalista da sociologia, foi aplicado como diretriz fundamental do sistema de competência profissional da Inglaterra. Nesta abordagem interessam os resultados (produtos) e não os processos desenvolvidos para atingi-los. Listas de conhecimentos e de especificações de avaliação são agregadas às tarefas, 
LIMA, V. V.

porém sem que se estabeleça um vínculo entre atributos e tarefas, ou mesmo entre as próprias tarefas (Ramos, 2001; Valle, 2003).

$O$ construtivismo francês traz uma abordagem voltada à construção social de competência e à relação das capacidades individuais e coletivas, numa investigação participante que envolve trabalhadores/organizações $e$, embora alguns defendam a participação de formadores, essa abordagem é fortemente orientada pelo trabalho e diretamente referida aos conteúdos dos empregos típicos. Neste sentido, mesmo definida de uma maneira mais ampliada $e$ a partir do trabalho, a competência é expressa sob a forma de uma lista de atividades segundo emprego e, por isso, também focaliza os resultados (Bouyx, 1998; Ramos, 2001).

O modelo australiano, impulsionado pelo governo desse país, considera o contexto e a cultura do local de trabalho e confere à competência uma dimensão relacional entre tarefas e atributos. Embora partam do mundo do trabalho por meio do levantamento das tarefas ou ações, identificam os atributos que fundamentam a realização dessas ações, incorporando a ética e os valores como elementos integrantes do desempenho competente (Hager E Gonczi, 1996; Gonczi et al., 1998; Ramos, 2001).

Assim, a construção de currículos e programas educacionais orientados por competência seleciona os conteúdos legítimos e relevantes para a formação e define seus processos pedagógicos para o desenvolvimento prioritário:

. de tarefas e resultados (fazer) fundamentadas por um modelo comportamental da educação e psicologia;

. de atributos, fortemente centrados no conhecimento (saber), uma vez que quem sabe ou conhece é capaz de fazer; ou

. da prática profissional em diferentes contextos, a partir de uma combinação de atributos empregados para a realização de ações, segundo padrões de excelência socialmente construídos.

Historicamente, o desenvolvimento da concepção de competência na educação tem fortes raízes no comportamentalismo (behaviorismo), $e$ influenciou a organização curricular nos anos 1960 e 1970. Essa influência ainda é marcante na formação de profissionais técnicos de nível médio $e$ traduz-se pela utilização de listas de tarefas e sub-tarefas, cuja realização é verificada mediante check lists. Essa abordagem está apoiada na premissa de que há uma "única e melhor maneira" de realizar as tarefas e ações da prática profissional.

A concepção dialógica de competência trabalha com o desenvolvimento de capacidades ou atributos (cognitivos, psicomotores e afetivos) que, combinados, conformam distintas maneiras de realizar, com sucesso, as ações essenciais e características de uma determinada prática profissional. Assim, diferentes combinações podem responder aos padrões de excelência que regem essa prática profissional, permitindo que as pessoas desenvolvam um estilo próprio, adequado e eficaz para enfrentar situações profissionais familiares ou não familiares. Essa abordagem, considerada holística, precisa ser construída no diálogo entre a formação e o mundo do trabalho, na qual as práticas profissionais são desenvolvidas.

Assim, é na ação, no desempenho perante as situações da prática que o 
estudante pode utilizar conhecimentos e habilidades resignificados por meio do conjunto de seus valores pessoais. A "capacidade de mobilizar diferentes recursos (....) para solucionar com pertinência e eficácia uma série de situações" foi conceituada como competência por diversos autores da área educacional (Hager et al., 1994; Hager E Gonczi, 1996; Perrenoud, 1999; Hernández, 2002).

A competência não é algo que se possa observar diretamente, mas pode ser inferida pelo desempenho. Numa determinada profissão, agrupamentos de desempenhos de natureza afim conformam áreas de competência complementares. Neste sentido, o conceito de competência profissional é empregado no singular, pois retrata a síntese de conjuntos de desempenhos (capacidades em ação) agrupados em áreas de competência que conformam o campo da prática profissional, segundo contexto e padrões de excelência.

É importante ressaltar que, na perspectiva construtivista, tampouco o conceito de desempenho se restringe a uma série de tarefas discretas, definidas de modo tecnificado e avaliadas por uma abordagem descontextualizada e fragmentada. Um enfoque de competência centrado nesta abordagem reduzida de desempenho implica a subestimação do desenvolvimento e da avaliação das capacidades que subjazem $e$ fundamentam os desempenhos, centrando a aprendizagem e sua certificação na verificação do cumprimento de tarefas.

Por outro lado, um enfoque de competência centrado só nas capacidades/ atributos corre o risco de favorecer o desenvolvimento desarticulado dos domínios cognitivo, psicomotor e afetivo e de reduzir a prática a simples campo de aplicação da teoria.

Formação orientada por competência: pressupostos psicopedagógicos Dimensões psicológica e pedagógica fundamentam tanto as teorias sobre a aprendizagem como a formação por competências. Embora não se conheçam todas as possíveis maneiras e processos usados pela mente para aprender, sabe-se que a aprendizagem, como uma mudança permanente na relação entre as pessoas e destas com a sociedade, pode ser desenvolvida de diversas maneiras (Coll, 2000).

Sabe-se, também, que em nenhuma outra espécie essa relação com a vida coletiva tem uma influência tão profunda sobre o desenvolvimento do indivíduo como ocorre com os seres humanos. Sem a aprendizagem não seríamos capazes de funcionar como pessoas e membros de um grupo, ou sociedade (Elias, 2001).

A combinação entre os elementos "experiência", "ambiente", $e$ "capacidades individuais/maturação" permite a constituição das diferentes maneiras de aprender. Desde a habituação (estímulo-resposta) e os condicionamentos clássicos e operantes até a formação de comportamentos complexos.

A aprendizagem por condicionamento (teoria comportamentalista), considerada, por muito tempo, uma das alternativas mais importantes para propiciar a aprendizagem, concebia a aprendizagem dos seres humanos somente como resposta aos estímulos do ambiente. A teoria cognitivista, por outro lado, elevou as pessoas a um patamar distinto ao compreendê-las 
como agentes/sujeitos e não meramente reagentes no processo de aprendizagem.

Considerando-se a idéia de um processo dinâmico na construção da aprendizagem (Piaget, 1995), outros pesquisadores apontaram que esse desenvolvimento também está condicionado por dimensões não exploradas na formulação da teoria genética; observaram que o contexto de vida, constituído pelas condições materiais e culturais (psicologia cultural), as experiências e a ação de terceiros na aprendizagem (teoria da atividade $e$ zona proximal de desenvolvimento), bem como a teoria de que existem muitos domínios de atividades que não são comuns a todas as crianças, mostraram que o desenvolvimento $e$ a aprendizagem ocorrem de modos distintos para as pessoas (Coll, 2000; Cole, 1981; Vygotsky, 1977; 1999).

A teoria da aprendizagem significativa (Ausubel et al., 1980) também ampliou outras dimensões da aprendizagem, destacando as repercussões das experiências educativas prévias sobre a assimilação do conhecimento novo e ressaltando duas condições para a construção de significado: um conteúdo potencialmente significativo e uma atitude favorável para aprender significativamente. Assim, a aprendizagem significativa requer do aprendiz uma postura pró-ativa que favoreça o estabelecimento de relações entre o novo e os elementos já presentes em sua estrutura cognoscitiva. Essa estrutura representa um conjunto de esquemas de conhecimento constituído por dados, conceitos, situações, fatos, seqüência de acontecimentos, ações e seqüências de ações, que podem estar mais ou menos organizados e coerentes e que permitem o estabelecimento de redes e relações de diferentes matizes de extensão e complexidade.

Segundo Coll (2000, p.60), os aspectos complementares das teorias de base cognitivista permitem apontar que "uma concepção construtivista da ação pedagógica pressupõe criar condições adequadas para que os esquemas de conhecimento, inevitavelmente construídos pelos estudantes, sejam os mais corretos e ricos possiveis". Para tanto, é preciso romper com o equilíbrio inicial dos esquemas com relação ao novo conteúdo da aprendizagem e à construção de novos significados. Porém, se o conteúdo novo não apresentar funcionalidade, isto é, possibilidade de utilização ou relação com as circunstâncias nas quais o estudante estiver envolvido, ele pode até memorizá-los, porém não há garantia a respeito do tempo de retenção, nem do grau de integração ou modificação que serão produzidas sobre as relações e esquemas de conhecimento previamente adquiridos.

$\mathrm{Na}$ abordagem dialógica de competência, a construção de significado pressupõe a transferência da aprendizagem baseada nos conteúdos para uma aprendizagem baseada na integração teoria-prática. É na reflexão e na teorização a partir das ações da prática profissional, preferencialmente realizadas em situações reais do trabalho, que estudantes e docentes constroem e desenvolvem capacidades. Orientar o processo ensinoaprendizagem por competência tem, por definição, um caráter prático $e$ social. Os conteúdos passam a ser explorados considerando-se o significado a eles atribuídos e sua consistência e funcionalidade para o enfrentamento de situações reais e complexas, segundo padrões de excelência socialmente definidos. 
O paradigma da prática reflexiva, ao integrar teoria e prática, constitui-se como processo de investigação da ação, articulando a criatividade revolucionária da prática ao potencial emancipatório da teoria e da reflexão (Girox, 1986; Moglika, 2003).

A utilização de situações reais ou simuladas da prática profissional garante uma aproximação imediata da aprendizagem ao mundo do trabalho, favorecendo a construção de novos saberes a partir do reconhecimento da prática em questão e do potencial significativo das ações observadas e/ou realizadas, assim como da funcionalidade das capacidades a serem desenvolvidas para melhor qualificar essas ações.

\section{Avaliação de competência: certificação profissional}

Os padrões de competência utilizados para certificação explicitam o que o profissional deve saber e ser capaz de fazer para desempenhar sua prática com sucesso, possibilitando o desenvolvimento de profissionalismo (padrões de qualidade). Refletem os valores atribuídos, por uma sociedade, a uma determinada carreira e orientam os processos de formação e de avaliação profissionais.

A certificação é um processo que pode ser impulsionado pelo Estado e/ou por setores da sociedade civil organizada. No entanto, é importante destacar que a garantia de participação e pactuação dos diferentes atores/instituições e segmentos interessados amplia a validação e credibilidade dos parâmetros utilizados para a formação e avaliação do desempenho dos profissionais de uma determinada carreira. A pactuação tem por base o reconhecimento da natureza social da construção do perfil, da competência, dos critérios de excelência e da necessidade de conferir legitimidade ao processo pela participação ativa e reflexiva dos atores relevantes envolvidos e interessados no processo.

A fragilidade do processo de avaliação, durante a graduação, pode ser revelada pela ocorrência de vários insucessos da prática profissional atribuídos à desqualificação da formação profissional ou à presença de valores pessoais incompatíveis com uma postura ética e de responsabilidade social no exercício da profissão. Se a avaliação focalizar apenas os aspectos cognitivos (saber) e/ou as habilidades e destrezas (fazer), a inadequação desse processo estará mantida, uma vez que reduz $e$ fragmenta a avaliação de competência.

Resignificar a avaliação no processo educacional é um eixo estruturante nas mudanças curriculares. Torná-la uma atividade inerente ao processo educacional e, por isso, contínua e sistematizada; reconhecê-la como uma das atividades educacionais mais expressivas do ponto de

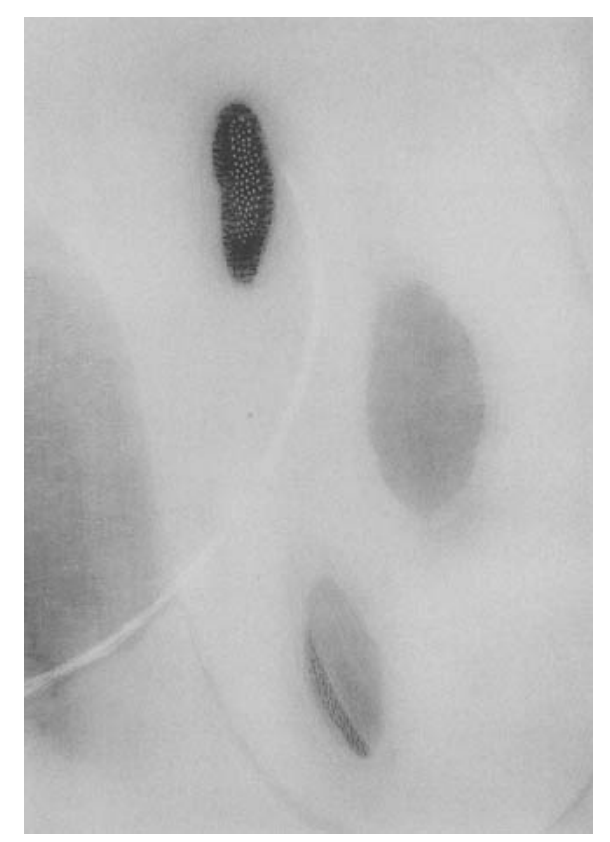


LIMA, V. V.

vista da mobilização dos aprendizes e, por isso, estratégica; ampliá-la pela análise integradora dos atributos pessoais em relação aos resultados obtidos $e$, por isso, orientada à avaliação da prática profissional. Finalmente, assegurar a coerência entre as avaliações de processo (formativas) $e$ as avaliações que definem a progressão dos estudantes (somativas) e dessas duas com o perfil profissional desejado e os princípios filosóficos, pedagógicos e ideológicos do programa (Lima, 2004).

Competência nos programas da área da saúde

$\mathrm{Na}$ área da saúde, este tema também tem ocupado um espaço cada vez mais expressivo e relevante levando-se em conta a ampliação da cobrança da sociedade por uma maior responsabilidade social, por parte das instituições formadoras e dos próprios profissionais, além dos desdobramentos desencadeados pelo processo de globalização, que passa a requerer padrões universalizados para intercâmbio.

No Brasil, novas exigências na formação profissional em saúde estão refletidas nas Diretrizes Curriculares Nacionais dos Cursos de Graduação em várias carreiras, inclusive Medicina, e propõem um novo perfil profissional fundamentado no desenvolvimento e na avaliação de competência dos egressos desses programas.

O desafio de participar ativamente da construção desse novo perfil profissional para as carreiras da saúde vem constituindo uma importante abertura para a discussão das diferentes concepções de competência $e$, ainda, numa oportunidade de transformação da prática profissional. Experiências instigantes, apoiadas por organizações internacionais, foram desencadeadas principalmente em programas de medicina e enfermagem, em algumas instituições brasileiras, a partir da década de 1990 (Feuerwerker, 2002).

As atuais políticas nacionais de saúde e de educação apontam para a necessidade de mudanças nos processos de formação profissional e têm estimulado e apoiado iniciativas no sentido da ampliação da responsabilidade social e da pactuação para a definição de competência e para o desenvolvimento das diretrizes curriculares nacionais. Cabe ressaltar que, embora as diretrizes curriculares sejam uma síntese das perspectivas de diferentes atores envolvidos na formação $e$ apresentem os elementos $e$ as dimensões dos novos perfis profissionais desejados, não há nenhuma explicitação da concepção de competência utilizada, existindo, ainda, uma certa confusão no emprego dos termos competência $e$ habilidades.

O debate sobre campo e núcleo do trabalho profissional e, neste sentido, sobre as áreas de competência que caracterizam as diferentes carreiras da saúde também são aspectos importantes na definição de competência $e$, mais especificamente, na significação do processo de trabalho em equipes de saúde (Campos, 2003).

A orientação dos currículos por competência, na área da saúde, implica a inserção dos estudantes, desde o início do curso, em cenários da prática profissional com a realização de atividades educacionais que promovam o desenvolvimento dos desempenhos (capacidades em ação), segundo contexto e critérios. Nesse sentido, cabe ressaltar como aspectos de progressão do estudante o desenvolvimento crescente de autonomia $e$ domínio em relação às áreas de competência. Essa inserção pressupõe uma

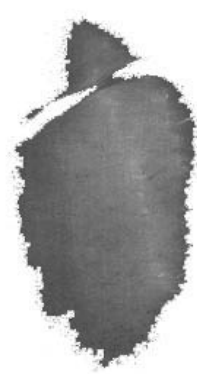


estreita parceria entre a academia e os serviços de saúde, uma vez que é pela reflexão e teorização a partir de situações da prática que se estabelece o processo de ensino-aprendizagem.

A organização curricular passa a focalizar o desenvolvimento das áreas de competência com a integração e exploração dos conteúdos a partir de situações-problema reais ou simulados da prática profissional. Essas situações representam estímulos para o desencadeamento do processo ensino-aprendizagem. Nas situações reais, sob supervisão, a responsabilização e o vínculo desenvolvidos pelos estudantes com pacientes, com as equipes de saúde e com a própria organização e avaliação dos serviços prestados também são considerados elementos constitutivos da competência.

$\mathrm{Na}$ abordagem dialógica de competência, há uma forte mudança no papel dos serviços e dos profissionais de saúde na formação profissional.

Conseqüentemente, há também uma mudança no papel da escola e dos docentes na relação com estudantes e com os parceiros. Os referenciais dessa mudança encontram-se ancorados no reconhecimento dos diferentes saberes e perspectivas dos atores envolvidos na formação e no princípio de que não há subordinação e sim complementariedade na integração teoriaprática.

Embora a parceria academia-serviço seja historicamente utilizada na realização de estágios em todas as carreiras da área da saúde, geralmente os profissionais dos serviços ficam responsáveis pela supervisão do desempenho dos estudantes e os docentes pela teorização e supervisão geral do estágio. Num currículo orientado por competência o trabalho de apoio e de facilitação ao desenvolvimento de capacidades dos estudantes em situações reais ocorre em ação e, por isso, a prática educacional ganha novo sentido. Dessa forma, docentes e profissionais dos serviços necessitam construir e/ou resignificar suas próprias capacidades tanto na área educacional como na área de cuidado à saúde de pacientes e comunidades.

A relação educacional, como constrói e resignifica saberes, requer maior horizontalização, ação cooperativa, solidária e ética, postura ativa, crítica $e$ reflexiva, desenvolvimento da capacidade de aprender a aprender, identificação dos próprios valores e abertura para a superação de limites $e$ constrições. A avaliação ocupa um espaço estratégico tanto no desenvolvimento e melhoria do processo ensino-aprendizagem, como na própria gestão curricular.

\section{Considerações finais}

No contexto da formação de profissionais de saúde, a abordagem dialógica de competência possibilita a reflexão sobre as práticas profissionais e uma construção dialogada entre os mundos da escola e do trabalho com a sociedade, a partir da explicitação de diferentes interesses, valores e saberes, social e historicamente constituídos. Os currículos orientados por esta abordagem são desenvolvidos em torno de eixos que articulam e integram: teoria e prática; capacidades e ações; contextos; e critérios de excelência.
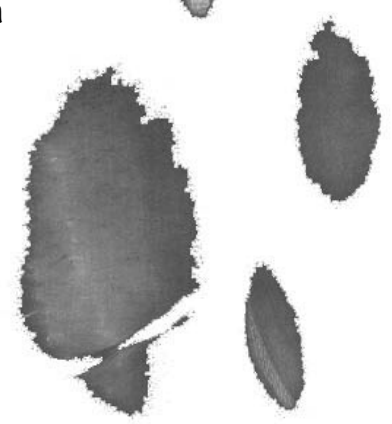
LIMA, V. V.

A noção de competência como construção social e o caráter reflexivo e dialógico dessa construção são elementos distintivos desta abordagem, num campo em que a polissemia do termo traduz disputas sobre o papel das escolas nas sociedades.

Embora haja resistência ao processo reflexivo sobre nossas práticas profissionais, que realmente considere a perspectiva de outros atores, $e$ insegurança em relação aos elementos inovadores dessa abordagem, ressalta-se que as atuais políticas de saúde e de educação têm estimulado iniciativas e oferecido oportunidades que podem ser consideradas como fatores positivos para o enfrentamento dessas dificuldades. Neste sentido, a construção de competência na abordagem dialógica e sua tradução curricular apresenta-se como uma alternativa consistente e estratégica para a formação de profissionais de saúde orientada às necessidades sociais, porém ainda um desafio a ser conquistado.

\section{Referências}

AUSUBEL, D.; NOVAK, J.D.; HANESIAN, H. Psicologia educacional. Rio de Janeiro: Interamericana, 1980.

BOLTANSKY, L; CHIAPELLO, È. Le nouvel espirit du capitalisme. Paris: Éditions Gallimard, 2001. BOUYX, B. El sistema francês de formación profesional. In: ARGÜLLES, A (Comp.) La educación tecnológica en el mundo. México: Editorial Limusa, 1998. p.31-50.

BURAWOY, M. Manufacturing consent: changes in the labor process under monopoly capitalism. NY: The University of Chicago Press, 1979.

CAMPOS, G.W.S. Um método para análise de co-gestão de coletivos. São Paulo: Hucitec, 2000.

CAMPOS, G.W.S. Saúde Paidéia. São Paulo: Hucitec, 2003.

COLE, M. Society, mind and development. CHIP Report 106. San Diego: University of California Press, 1981.

COLL, C. Psicologia e currículo: uma aproximação psicopedagógica à elaboração do currículo escolar. São Paulo: Ática, 2000.

ELIAS, N. A solidão dos moribundos: envelhecer e morrer. Rio de Janeiro: Jorge Zahar, 2001.

FEUERWERKER, L.C.M. Além do discurso de mudança da Educação Médica: processos e resultados. São Paulo: Hucitec, 2002.

GIROX, H. Praticando estudos culturais nas faculdades de educação. In: SILVA, T. (Org.) Alienígenas na sala de aula: uma introdução aos estudos culturais em educação. Petrópolis: Vozes, 1995. p.93124.

GONCZI, A.; HEGERTY, F.; WOODBURNE, G. Temas actuales de la educación y la capacitación professional en Australia. In: ARGÜILLES, A. (Org.) La educación en el mundo. México: Editorial Limusa, 1998. p.205-37.

HAGER, P.; GONCZI, A. What is competence? Medical Teacher, v.18, n.1, p.15-8, 1996.

HAGER, P.; GONCZI, A.; ATHANASOU, J. General issues about assessment of competence. Asses.

Eval. High. Educ., v.19, n.1, p.3-15, 1994.

HERNÁNDEZ, D. Políticas de certificación de competências em América Latina. In: CINTERFOR. 
Competencia Laboral y valorización del aprendizaje. Montevideo: Cinterfor/OIT. Boletín Técnico Interamericano de Formación Profesional, n.152, 2002.

HILLAU, B. De l'intelligence operatoire à l'historicité du sujet. In: MINET, F. PARLIER, M., WITTE, S.

(Orgs.) La compétence, mythe, construction ou réalité? Paris: Éditions Harmattan, 1994. p.4569.

LIMA, V.V. Avaliação de competência nos cursos médicos. In: MARINS, J.J.N.; REGO, S.; LAMPERT, J.B.; ARAÚJO, J.G.C. (Orgs.) Educação Médica em transformação: instrumentos para a construção de novas realidades. São Paulo: HUCITEC/ABEM, 2004. p.123-40.

MERLEAU-PONTY, M. De Mauss a Claude Levi-Strauss. São Paulo: Abril Cultural, 1980 (Coleção Os pensadores).

MOGLIKA, M. Educar para a Democracia. Cad. Pesqui., n.119, p.129-46, 2003.

PERRENOUD, P. Construir as competências desde a escola. Porto Alegre: Artmed, 1999.

PIAGET, J. Abstração reflexionante. Porto Alegre: Artmed, 1995.

RAMOS, M.N. A pedagogia das competências: autonomia ou adaptação? São Paulo: Cortez, 2001.

RIBEIRO, E.C.O. Representações de alunos e docentes sobre as práticas de cuidado e de formação: uma avaliação de experiências de mudança em escolas médicas. 2003. Tese (Doutorado) - Instituto de Medicina Social, Universidade do Estado do Rio de Janeiro, Rio de Janeiro.

VALLE, R. (Org.) O conhecimento em ação: novas competências para o trabalho no contexto da reestruturação produtiva. Rio de Janeiro: Relume Dumará, 2003.

VYGOTSKY, L.S. Pensamiento y lenguaje. Buenos Aires: La Pleyade, 1977.

VYGOTSKY, L.S. A formação social da mente. São Paulo: Martins Fontes, 1999.
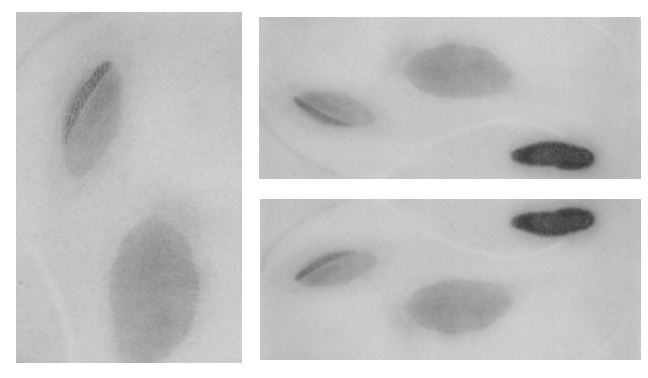

LIMA, V. V. Competencia: distintos abordajes e implicaciones en la formación de profesionales de la salud. Interface - Comunic., Saúde, Educ., v.9, n.17, p.369-79, mar/ago 2005.

Este artículo presenta algunas de las principales concepciones sobre currículos orientados por competencia, $y$ analiza esos distintos abordajes en función de la referencia teórica que los fundamenta, de sus dimensiones constituyentes y de las consecuentes implicaciones en la organización curricular. Señala al nuevo significado de competencia - traído por el abordaje dialógico - como un camino hacia la integración de la teoría y de la práctica en la formación de profesionales de la salud.

PALABRAS CLAVE: Educación; salud; currículo; competencia profesional; práctica profesional. 


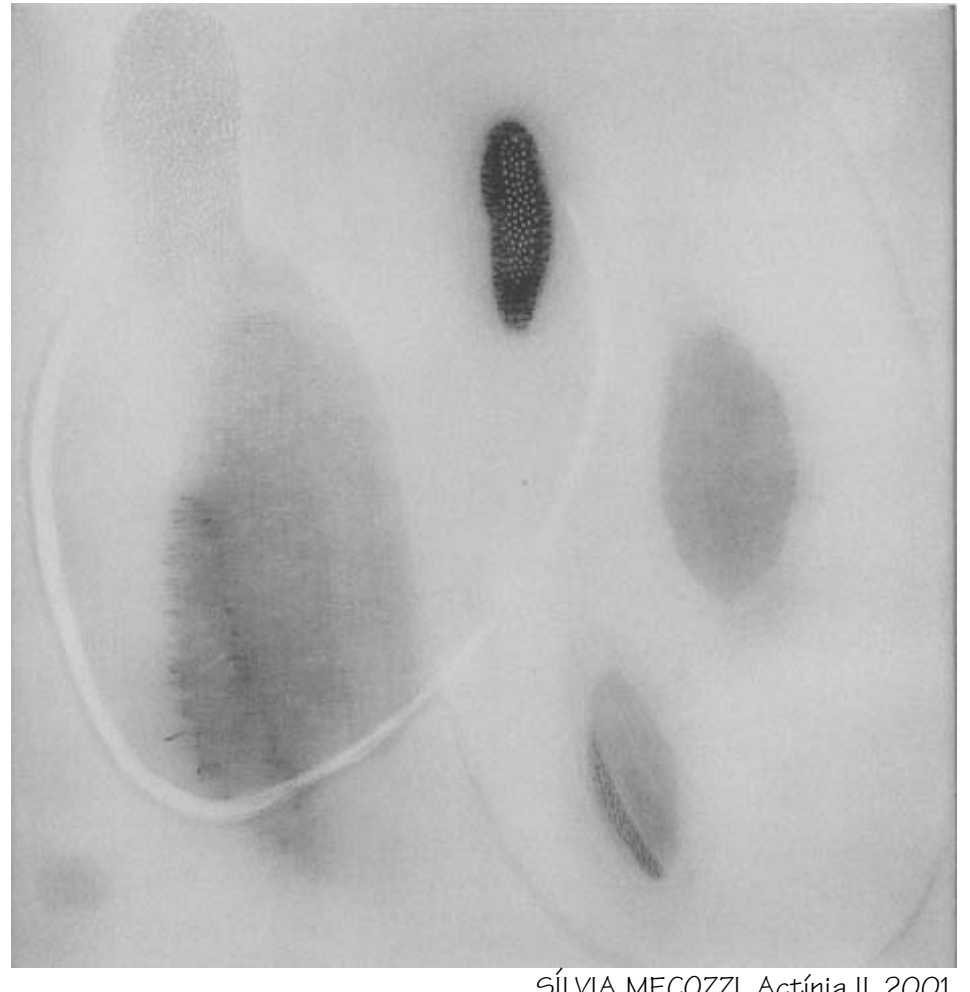

SÍLVIA MECOZZI, Actínia II, 2001

380 Interface - Comunic, Saúde, Educ, v.9, n.17, p.380, mar/ago 2005 